\title{
The significance of low PU.1 expression in patients with acute promyelocytic leukemia
}

\author{
Xuehua Zhu, Hui Zhang, Maoxiang Qian, Xujie Zhao, Wentao Yang, Ping Wang, Ji Zhang and Kankan Wang*
}

\begin{abstract}
Background: Although the importance of the hematopoietic transcription factor PU.1 in acute myeloid leukemia (AML) has been demonstrated, the expression of PU.1 in acute promyelocytic leukemia (APL) patient samples awaits further investigation. The current study used APL patient samples to assess the expression pattern of PU.1 in the initiation and progression of APL.

Findings: We used real-time RT-PCR to compare PU.1 expression between de novo APL patient samples and normal blood specimens, and the results indicated that PU.1 expression was significantly lower in newly diagnosed APL patient samples as compared to normal hematopoietic cells. Further evidence showed a significant inverse correlation between the expression level of PML-RARa and that of PU.1. In addition, we analyzed the correlation between PML-RARa and PU.1 expression in a large population of AML patients retrieved from the expression profiles. The results showed that PU.1 expression was lower in patients with APL than other AML subtypes and there was also a trend towards increasing PU.1 expression from AML-M0 to AML-M5, with the exception of AML-M3 (APL). These observations suggested that PU.1 expression was reduced by PML-RARa in APL patients. Furthermore, we measured PU.1 expression in APL-initiating cells isolated from de novo APL patients by side population cell analysis and found that suppression of PU.1 expression occurred concurrently with PML-RARa expression, indicating the pivotal role of PU.1 in APL initiation.
\end{abstract}

Conclusion: Our findings provide evidence that low PU.1 expression in APL patients is required for disease initiation and progression.

Keywords: PML-RARa, PU.1, Acute promyelocytic leukemia

\section{Introduction}

Acute promyelocytic leukemia (APL) is typified by the $t(15 ; 17)$ translocation, which generates the PML-RAR $\alpha$ fusion protein and produces a beneficial response to alltrans retinoic acid (ATRA) and arsenic trioxide [1]. At the molecular level, PML-RAR $\alpha$ affects the normal functions of wild-type PML and RAR $\alpha$ signaling. However, PML- or RAR $\alpha$-deficient mice display few obvious defects $[2,3]$. Furthermore, in PML-RAR $\alpha$ transgenic mice, on average, only 30\% develop APL after a long latent period of observation [4], suggesting that APL development may require

\footnotetext{
* Correspondence: kankanwang@shsmu.edu.cn

State Key Laboratory of Medical Genomics, Institute of Health Sciences, Shanghai Institutes for Biological Sciences, Chinese Academy of Sciences (CAS) \& Shanghai Jiao Tong University School of Medicine (SJTUSM) and Shanghai Institute of Hematology, Rui-Jin Hospital, SJTUSM, Shanghai 200025, China
}

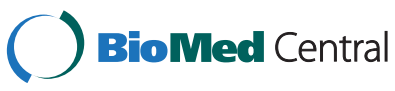

(C) 2012 Zhu et al.; licensee BioMed Central Ltd. This is an Open Access article distributed under the terms of the Creative Commons Attribution License (http://creativecommons.org/licenses/by/2.0), which permits unrestricted use, distribution, and reproduction in any medium, provided the original work is properly cited. additional genetic events that are indispensable for myeloid differentiation.

Recently, we demonstrated that PML-RAR $\alpha$ interferes with the function of PU.1, which results in a block of downstream PU.1 signaling [5]. In addition, the study by Mueller BU et al. also reported that PU.1 is suppressed by PML-RAR $\alpha$ and that ATRA treatment is capable of restoring PU.1 expression [6]. Although these findings have been confirmed using cell lines, there is a growing evidence to suggest that cell lines do not fully recapitulate the biology of human disease. Therefore, to most accurately examine the role of PU.1 in APL, investigation into the expression profile of PU.1 in APL patient samples is required.

\section{Materials and methods \\ Patient samples and human umbilical cord blood \\ The study was approved by the Ethics Committee of Ruijin Hospital affiliated to Shanghai Jiaotong University School}


of Medicine and was adherent to the regulations of the declaration of Helsinski. Bone marrow specimens were obtained after receiving informed consent from patients at the time of their diagnosis with de novo APL (Table 1). Peripheral blood specimens were obtained from healthy volunteers with informed consent. Umbilical cord blood (UCB) specimens were obtained with informed consent from volunteer donors attending the obstetrics department at Ruijin Hospital.

\section{Cell preparation}

Mononuclear cells and granulocytes were isolated using Ficoll-Paque (Lymphoprep ${ }^{\mathrm{TM}}$, Fresenius Kabi Norge AS, Norway) density gradient separation. $\mathrm{CD}^{+} 4^{+}$cells were isolated from UCB specimens using a high magnetic gradient MiniMACS purification system (Miltenyi, Sunnyvale, CA).

Side population analysis of fresh APL and UCB specimens Side population (SP) cell analysis was performed according to the protocol from Goodell's laboratory [7] with minor modifications.

\section{Real-time RT-PCR}

Total RNA was extracted from cells using an RNeasy Kit from Qiagen (Chatsworth, CA). Reverse transcription was performed using the Superscript II reagent set (Invitrogen, Carlsbad, CA) with random hexamer primers. Quantitative real-time PCR was performed using an ABI Prism 7900HT detection system (Applied Biosystems, Foster City, CA). The relative expression level for each target in comparison to the internal control GAPDH was calculated using the following equation: $\Delta \mathrm{Ct}=\mathrm{Ct}$ (target) $-\mathrm{Ct}$ $(\mathrm{GAPDH})$, where the relative mRNA expression $=2^{-\Delta \mathrm{Ct}} \times$ 100. Each assay was performed in triplicate.

The expression of PML-RAR $\alpha$, PU.1 and GAPDH mRNA in cells was analyzed by real-time PCR with the following primers corresponding to distinct sequences: sense (5'-AAGTGAGGTCTTCCTGCCCAA-3') and antisense
(5'-GGCTGGGCACTATCTCTTCAGA-3') for PML-RAR $\alpha$; sense (5'-AGAAGAAGATCCGCCTGTACCA-3') and antisense (5'-GTGCTTGGACGAGAACTGGAA-3') for PU.1; sense (5'-GAAGGTGAAGGTCGGAGTC-3') and antisense (5'- GAAGATGGTGATGGGATTTC-3') for GAPDH.

\section{Gene expression analysis}

The raw gene expression data and clinical data from four cohorts of AML patients were provided by other research groups [8-11]. To perform interarray comparisons, the CEL files were analyzed using Affymetrix MAS 5.0 software. The PU.1 expression level relative to that of GAPDH was calculated as $\log _{2}(10000 \times$ expression level of PU.1 / expression level of GAPDH). Two-tailed $t$ tests were used to validate the significance of the observed differences.

\section{Results}

PU.1 expression is significantly lower in APL patient samples in comparison to normal hematopoietic cells We first examined PU.1 mRNA expression in mononuclear cells from 10 newly diagnosed APL patients with high percentages of blasts (> 80\%, mean 91\%) (Table 1). The peripheral blood cells isolated from 7 healthy volunteers and the normal hematopoietic stem cell-enriched $\mathrm{CD} 4^{+}$cells isolated from 8 fresh human UCB specimens served as controls. As shown in Figure 1, PU.1 expression was significantly lower in the primary APL samples in comparison to normal hematopoietic cells, including white blood cells (WBCs), mononuclear cells (MNCs), granulocytes and immature progenitor cells $\left(p=7.6 \times 10^{-7}\right.$, $4.6 \times 10^{-4}, 1.5 \times 10^{-7}$ and 0.015 , respectively).

\section{PU.1 is expressed at lower levels in patients with APL as compared to other AML subtypes}

To draw more solid conclusions, we retrieved four datasets containing the expression profiles of 595 AML patients, 79 APL patients and 516 patients with other AML subtypes [8-11] and compared PU.1 expression between APL patients and non-APL AML patients. A

Table 1 Characteristics of the patient population

\begin{tabular}{|c|c|c|c|c|c|c|c|}
\hline Patient no & Age & Sex & Blasts (\%) & WBC $\left(\times 10^{9} / L\right)$ & HGB (g/L) & Platelets $\left(\times 10^{9} / \mathrm{L}\right)$ & Karyotype \\
\hline APL1 & 53 & M & 92.5 & 4.9 & 105 & 64 & $46, X Y, t(15 ; 17)(q 22 ; q 12)[7] / 46, X Y[2]$ \\
\hline APL2 & 47 & M & 82 & 3.3 & 100 & 7 & $46, X Y, t(15 ; 17)(q 22 ; q 12)$ \\
\hline APL3 & 31 & M & 91 & 15.1 & 100 & 17 & ND \\
\hline APL4 & 65 & M & 95.5 & ND & ND & ND & $46, X Y, t(15 ; 17)(q 22 ; q 12)[8] / 46, X Y[3]$ \\
\hline APL5 & 34 & M & 97.5 & 2.04 & 57 & 45 & $46, X Y, t(15 ; 17)(q 22 ; q 12)$ \\
\hline APL6 & 51 & $\mathrm{~F}$ & 91 & 3.9 & 78 & 71 & $46, X X, t(15 ; 17)(q 22 ; q 12)[9]$ \\
\hline APL7 & 58 & $\mathrm{~F}$ & 85.5 & 5.6 & 101 & 62 & $46, X X, t(15 ; 17)(q 22 ; q 12)[10] / 46, X X[11]$ \\
\hline APL8 & 34 & $\mathrm{~F}$ & 98 & 7.5 & 117 & 34 & $46, X X, t(15 ; 17)(q 22 ; q 12)[10] / 46, X X[11]$ \\
\hline APL9 & 40 & M & 85.5 & 5.7 & 69 & 30 & $46, X Y, t(15 ; 17)(q 22 ; q 12)[12] / 46, X Y[3]$ \\
\hline APL10 & 24 & $M$ & 91 & 2.5 & 122 & 60 & $46, X Y, t(15 ; 17)(q 22 ; q 12)$ \\
\hline
\end{tabular}




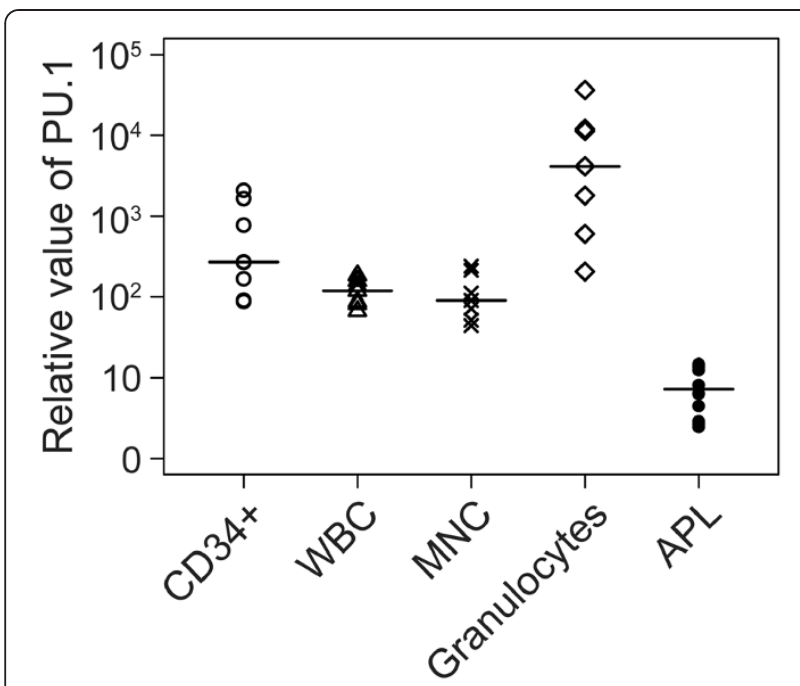

Figure 1 Lower level of PU.1 mRNA expression in de novo APL patients in comparison to normal hematopoietic cells. The relative PU.1 expression, as compared to that of the reference gene GAPDH, in leukemic cells freshly isolated from APL samples (Table 1), normal peripheral blood cells (WBCs, MNCs, and granulocytes) and CD34 ${ }^{+}$cells from human UCB specimens was determined using real-time RT-PCR. Each symbol represents the average value from an individual patient or healthy subject, and the lines indicate the median value.

genome-wide gene expression analysis of blasts from AML patients revealed that PU.1 was clearly expressed at a lower level in APL patients as compared to nonAPL patients (Figure 2A), indicating that PU.1 expression might be specifically reduced by PML-RAR $\alpha$ in APL. To further examine the relationship between PML-RAR $\alpha$ and PU.1, we compared the levels of PMLRAR $\alpha$ and PU.1 mRNA in the group of de novo APL patients shown in Table 1 . As expected, although there was considerable variation from patient to patient, a significant inverse correlation $(\mathrm{r}=-0.325)$ was observed between the expression level of PML-RAR $\alpha$ and PU.1 (Figure 2B), which is consistent with the findings by Mueller BU et al. [6]. These results indicate that PML-RAR $\alpha$ suppresses PU.1 expression in APL patients.

\section{PU.1 expression is particularly repressed in APL}

Furthermore, we evaluated PU.1 expression for each subtype of AML according to the French-American-British (FAB) classification. As shown in Figure 3, low PU.1 expression was observed in the M3 subtype (APL). Interestingly, in addition to the M3 subtype, low PU.1 expression was also observed in the M0, M6 and M7 subtypes. As a low level of PU.1 is a prerequisite for the differentiation of common myeloid progenitors (CMPs) to megakaryocyte/erythroid progenitors (MEPs) [12], it is
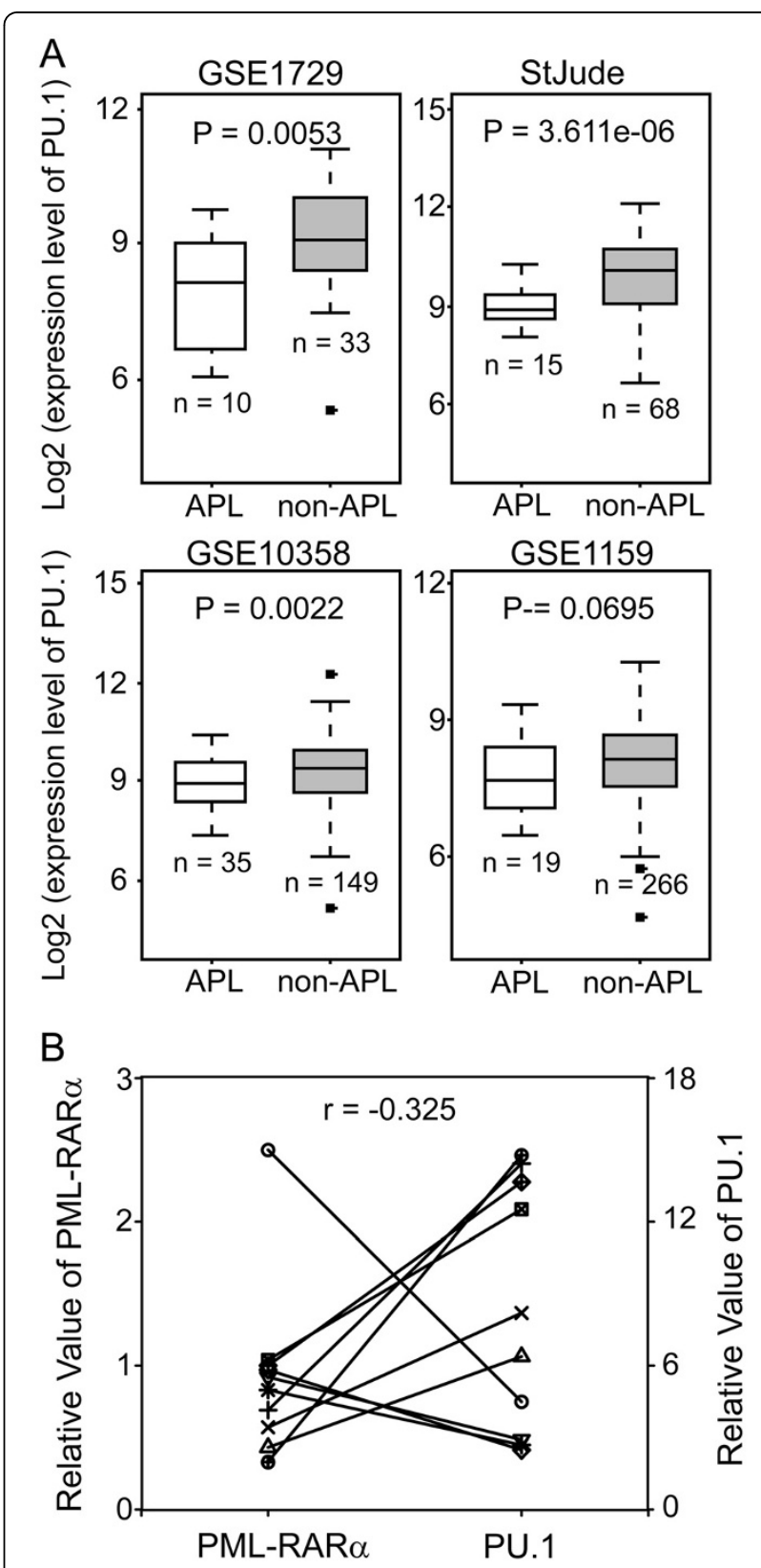

Figure 2 Lower levels of PU. 1 expression in APL patients as compared to non-APL AML patients. (A) Four representative gene expression profiling data sets were retrieved, including GSE1729, Stude, GSE10358 and GSE1159. White boxes indicate the expression levels of PU.1 in APL patients, and gray boxes represent the levels of PU.1 in non-APL (other AML subtypes) patients. The differences between the two groups were assessed using the two-tailed $t$ test. The $p$-values are shown in the panels. (B) The inverse correlation between PML-RARa and PU.1 mRNA expression was assessed by quantitative real-time RT-PCR using 10 fresh APL patient samples (Table 1). The correlation coefficient for PML-RARa versus PU.1 was $r=-0.325$. Each symbol represents the average values from individual patients.

reasonable that PU.1 levels would be lower in the M6 (acute erythroleukemia) and M7 (acute megakaryocytic leukemia) subtypes. The observation that PU.1 expression 


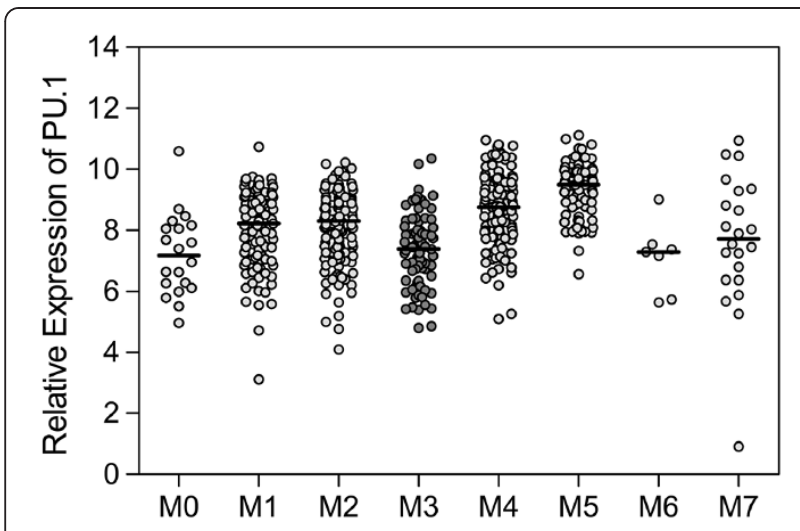

Figure 3 Particularly low levels of PU.1 expression in patients with APL as compared to other AML subtypes. AML patients were divided into eight subtypes (M0, M1, M2, M3, M4, M5, M6 and M7) according to FAB classification. The expression levels of PU.1 in the eight subtypes were evaluated. The four profiling data sets of AML patients, including GSE1729, StJude, GSE10358 and GSE1159, were combined. The PU.1 level relative to that of GAPDH was calculated as described in the Materials and methods.

appeared low in the M0 subtype (the most immature FAB subtype) may be explained by the fact that PU.1 expression is low in bone marrow cells lacking definitive signs of myeloid differentiation [12]. In addition, Figure 3 shows a trend towards increasing PU.1 expression from M0 to M5 with the exception of M3, which supports the notion that PU.1 expression is specifically repressed by PML-RAR $\alpha$.

\section{PU.1 is suppressed in APL initiation}

Growing evidence suggests that leukemia-initiating cells are responsible for initiating and sustaining the growth of the disease. Therefore, we evaluated the expression of PU.1 in APL-initiating cells. Unlike other subtypes of AML, most APL cells lack the CD34 ${ }^{+}$surface marker [13]. Zheng X et al. recently isolated SP cells from APL cells [14], and these cells have been reported to be highly enriched for cancer-initiating cells [15]. Therefore, we isolated SP cells from 4 de novo APL patient samples (Figure 4A), and SP cells from 4 human UCB specimens were included as controls. As shown in Figure 4B, the expression level of PU.1 was markedly lower in SP cells from primary APL samples in comparison to those from UCB specimens, indicating that the expression of PU.1 during APL initiation is reduced by PML-RAR $\alpha$.

\section{Discussion}

PU.1 not only plays an importance role in normal hematopoiesis but is also strongly implicated in leukemo genesis. By comparing PU.1 expression between APL patients and normal blood samples, we found that PU.1 expression was significantly lower in APL patients. By analyzing the expression pattern of PU.1 across a large scale of AML patients, we found that PU.1 expression was significantly lower in patients with APL compared to other AML subtypes. These observations may have been the result of the distinctive expression of PML-RAR $\alpha$, which suggests a connection between PML-RAR $\alpha$ expression and the decreased expression of PU.1 in APL. Taken together, these data indicate that low PU.1 expression may be a contributing event in APL.

The level of PU.1 expression is critical for hematopoietic lineage commitment and maturation [12]. PU.1 expression is low in hematopoietic stem cells (HSCs), and is upregulated at the CMP stage. CMPs with relatively high levels of PU.1 are mainly committed to the granulocyte and macrophage lineages, whereas those with relatively low levels of PU.1 are committed to the erythrocyte and megakaryocyte lineages [16]. AML is characterized by the blockage of myeloid differentiation at different stages, and FAB classification (M0 to M7) is generally performed according to the type of cells from which leukemia developed as well as their degree of maturity. The observed trend towards increasing PU.1 expression from M0 to M5 (except for M3) may reflect differentiation-related differences in PU.1 expression. Lower PU.1 expression was detected in undifferentiated (M0) AML confirms the finding that low PU.1 expression is present in blasts with minimal differentiation [12]. The intermediate PU.1 expression observed in myeloid (M1/2) AML and the high PU.1 expression observed in myelomonocytic (M4/5) AML are likely associated with the stage at which myeloid differentiation is blocked. Moreover, in regards to the increasing expression from M0 to M5, PU.1 expression in APL (M3) was exceptional and was detected at a significantly lower level, which was likely attributable to distinctive PML-RAR $\alpha$ expression at this stage. In vivo animal studies have also shown that functional disruption of PU.1 or a graded reduction in its expression blocks myelomonocytic differentiation or maturation, resulting in the accumulation of myeloid blasts and, thus, the genesis of myelogenous leukemia [17,18]. The differentiation of preleukemic cells in these mice was mostly blocked at the immature granulocytic stage, which suggests that other abnormalities may also influence PU.1 expression. Indeed, AML1-ETO has been reported to suppress PU.1 expression [19]. Although PU.1 expression was greater in the M2 stage than the M3 stage, this may have been due to the fact that $70-80 \%$ of M2 do not have AML1-ETO expression [20]. A more detailed classification for distinguishing between cell types would help to confirm the role of PU.1 in the development of AML. In addition, low PU.1 expression in erythrocytic (M6) and megakaryocytic (M7) AML supported the observation that PU.1 expression was reduced in the erythrocyte and megakaryocyte lineages [12]. Taken together, our data demonstrate that PML-RAR $\alpha$ expression together with reduced PU.1 expression is a characteristic of APL. 

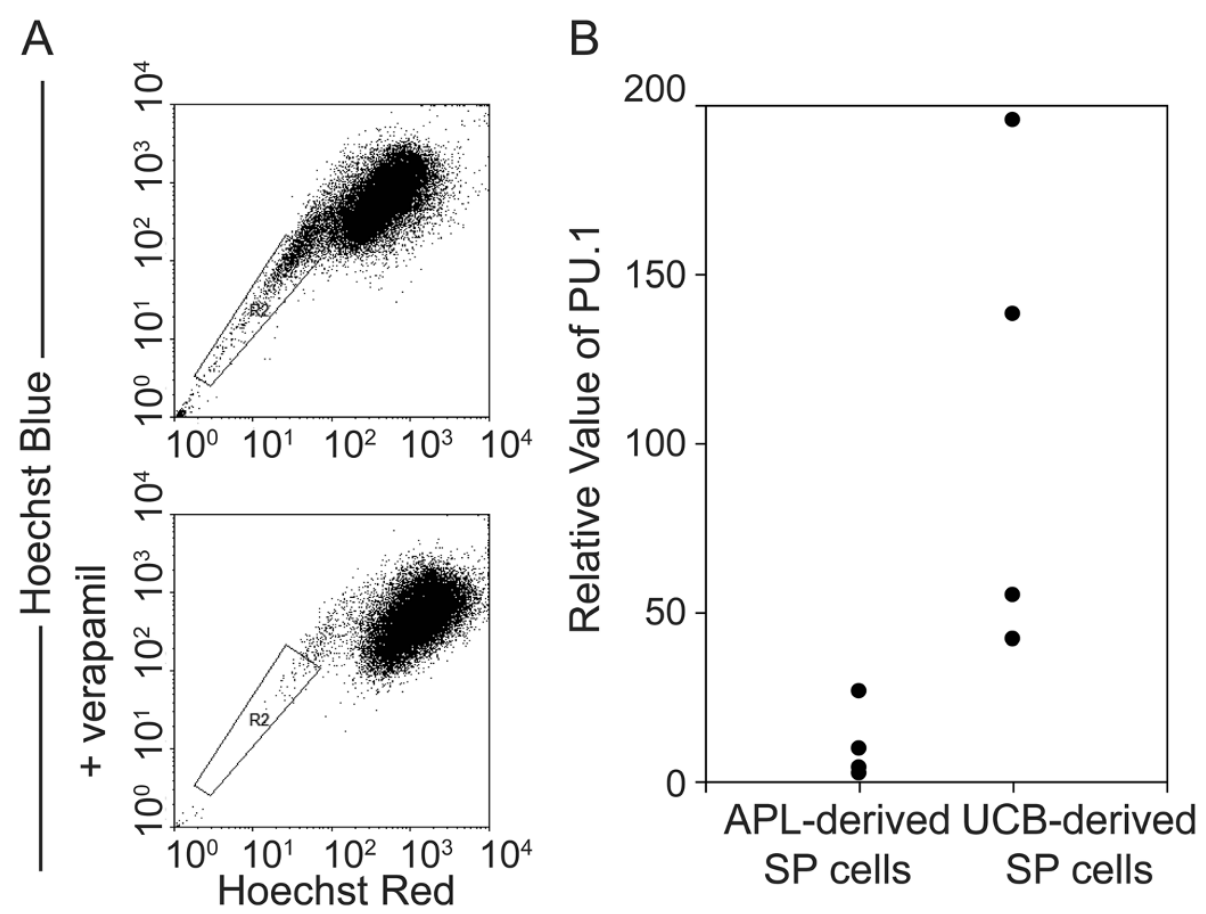

Figure 4 Lower levels of PU.1 expression in APL-initiating cells. (A) SP cell analysis. The SP cells were gated in the R2 box and were detected following Hoechst 33342 and verapamil co-treatment. Hoechst staining of APL mononuclear cells in the absence or presence of verapamil is shown in the upper and lower panels, respectively. The FACS profiles represent the results of the flow cytometry analysis of SP cells from APL samples. (B) Lower PU.1 levels in APL-derived SP cells as compared to UCB-derived SP cells. The PU.1 mRNA expression levels of SP cells from UCB specimens or primary APL samples were measured using real-time RT-PCR and were normalized to GAPDH expression. Each symbol represents the average value from an individual patient or UCB specimen.

Numerous studies have demonstrated that the initiation of APL requires the expression of PML-RAR $[21]$. However, PML-RAR $\alpha$ alone is not sufficient to induce APL [22-24]. Walter et al. demonstrated that transgenic mice expressing PML-RAR $\alpha$ frequently develop APL in association with the deletion of PU.1 [25]. Moreover, the penetrance rate for APL development was significantly increased when PML-RAR $\alpha$ mice were crossed with PU.1+/- mice [25]. Consistent with the above observations, our study found that PU.1 expression was lower during APL initiation using SP cells isolated from APL patient samples.

In conclusion, our data reveal the expression pattern of PU.1 in APL patient samples and provide additional clues about the mechanisms in the initiation and progression of APL. Therefore, we conclude that the formation of PMLRAR $\alpha$ and the subsequent suppression of PU.1 expression are critical for the initiation and progression of APL.

\section{Abbreviations}

APL: Acute promyelocytic leukemia; AML: Acute myeloid leukemia; ATRA: Alltrans retinoic acid; UCB: Umbilical cord blood; SP: Side population; WBC: White blood cell; MNC: Mononuclear cells; CMP: Common myeloid progenitor; FAB: French-American-British; MEP: Megakaryocyte/erythroid progenitor; HSC: Hematopoietic stem cell.

\section{Competing interests}

The authors declare that they have no competing interest.

\section{Acknowledgments}

This work was supported in part by Ministry of Science and Technology of China Grants (2009CB825607, 2012AA02A211 and 2011CB910202) and National Natural Science Foundation Grants (31171257, 90919059 and 30971623).

\section{Authors' contributions}

$\mathrm{XHZ}$ designed the study, performed experiments and wrote the manuscript: $\mathrm{HZ}$ and XJZ recruited samples and performed experiments; WTY and MXQ participated in the statistical analyses; PW performed experiments; JZ and KKW designed the study, interpreted the results and wrote the manuscript. All authors read and approved the final manuscript.

Received: 2 April 2012 Accepted: 8 May 2012

Published: 8 May 2012

\section{References}

1. Wang $Z Y$, Chen $Z$ : Acute promyelocytic leukemia: from highly fatal to highly curable. Blood 2008, 111:2505-2515.

2. Wang ZG, Delva L, Gaboli M, Rivi R, Giorgio M, Cordon-Cardo C, Grosveld F, Pandolfi PP: Role of PML in cell growth and the retinoic acid pathway. Science 1998, 279:1547-1551.

3. Kastner $P$, Chan S: Function of RARalpha during the maturation of neutrophils. Oncogene 2001, 20:7178-7185.

4. Grisolano JL, Wesselschmidt RL, Pelicci PG, Ley TJ: Altered myeloid development and acute leukemia in transgenic mice expressing PML-RAR alpha under control of cathepsin G regulatory sequences. Blood 1997, 89:376-387. 
5. Wang K, Wang P, Shi J, Zhu X, He M, Jia X, Yang X, Qiu F, Jin W, Qian M, Fang $H, M i$ J, Yang X, Xiao H, Minden M, Du Y, Chen Z, Zhang J: PML/RARalpha targets promoter regions containing PU.1 consensus and RARE half sites in acute promyelocytic leukemia. Cancer Cell 2010, 17:186-197.

6. Mueller BU, Pabst T, Fos J, Petkovic V, Fey MF, Asou N, Buergi U, Tenen DG: ATRA resolves the differentiation block in $\mathrm{t}(15 ; 17)$ acute myeloid leukemia by restoring PU.1 expression. Blood 2006, 107:3330-3338.

7. Goodell MA, Brose K, Paradis G, Conner AS, Mulligan RC: Isolation and functional properties of murine hematopoietic stem cells that are replicating in vivo. J Exp Med 1996, 183:1797-1806.

8. Gutierrez NC, Lopez-Perez R, Hernandez JM, Isidro I, Gonzalez B, Delgado M, Ferminan E, Garcia JL, Vazquez L, Gonzalez M, San Miguel JF: Gene expression profile reveals deregulation of genes with relevant functions in the different subclasses of acute myeloid leukemia. Leukemia 2005, 19:402-409.

9. Tomasson MH, Xiang Z, Walgren R, Zhao Y, Kasai Y, Miner T, Ries RE, Lubman O, Fremont DH, McLellan MD, Payton JE, Westervelt P, DiPersio JF, Link DC, Walter MJ, Graubert TA, Watson M, Baty J, Heath S, Shannon WD, Nagarajan R, Bloomfield CD, Mardis ER, Wilson RK, Ley TJ: Somatic mutations and germline sequence variants in the expressed tyrosine kinase genes of patients with de novo acute myeloid leukemia. Blood 2008, 111:4797-4808.

10. Valk PJ, Verhaak RG, Beijen MA, Erpelinck CA, van Doorn-Khosrovani Barjesteh van Waalwijk, Boer JM, Beverloo HB, Moorhouse MJ, van der Spek PJ, Lowenberg B, Delwel R: Prognostically useful gene-expression profiles in acute myeloid leukemia. N Engl J Med 2004, 350:1617-1628.

11. Ross ME, Mahfouz R, Onciu M, Liu HC, Zhou X, Song G, Shurtleff SA, Pounds S, Cheng C, Ma J, Ribeiro RC, Rubnitz JE, Girtman K, Williams WK, Raimondi SC, Liang DC, Shih LY, Pui CH, Downing JR: Gene expression profiling of pediatric acute myelogenous leukemia. Blood 2004, 104:3679-3687.

12. Dahl R, Simon MC: The importance of PU.1 concentration in hematopoietic lineage commitment and maturation. Blood Cells Mol Dis 2003, 31:229-233.

13. Sainty D, Liso V, Cantu-Rajnoldi A, Head D, Mozziconacci MJ, Arnoulet C, Benattar L, Fenu S, Mancini M, Duchayne E, Mahon FX, Gutierrez N, Birg F, Biondi A, Grimwade D, Lafage-Pochitaloff M, Hagemeijer A, Flandrin G: A new morphologic classification system for acute promyelocytic leukemia distinguishes cases with underlying PLZF/RARA gene rearrangements. Group Francais de Cytogenetique Hematologique, UK Cancer Cytogenetics Group and BIOMED 1 European Coomunity-Concerted Acion "Molecular Cytogenetic Diagnosis in Haematological Malignancies. Blood 2000, 96:1287-1296.

14. Zheng X, Seshire A, Ruster B, Bug G, Beissert T, Puccetti E, Hoelzer D, Henschler R, Ruthardt M: Arsenic but not all-trans retinoic acid overcomes the aberrant stem cell capacity of PML/RARalpha-positive leukemic stem cells. Haematologica 2007, 92:323-331.

15. Parmar K, Mauch P, Vergilio JA, Sackstein R, Down JD: Distribution of hematopoietic stem cells in the bone marrow according to regional hypoxia. Proc Natl Acad Sci U S A 2007, 104:5431-5436.

16. Nutt SL, Metcalf D, D'Amico A, Polli M, Wu L: Dynamic regulation of PU.1 expression in multipotent hematopoietic progenitors. J Exp Med 2005, 201:221-231.

17. Rosenbauer F, Wagner K, Kutok JL, Iwasaki H, Le Beau MM, Okuno Y, Akashi K, Fiering S, Tenen DG: Acute myeloid leukemia induced by graded reduction of a lineage-specific transcription factor, PU.1. Nat Genet 2004, 36:624-630.

18. Metcalf D, Dakic A, Mifsud S, Di RL, Wu L, Nutt S: Inactivation of PU.1 in adult mice leads to the development of myeloid leukemia. Proc Natl Acad Sci U S A 2006, 103:1486-1491.

19. Vangala RK, Heiss-Neumann MS, Rangatia JS, Singh SM, Schoch C, Tenen DG, Hiddemann W, Behre G: The myeloid master regulator transcription factor PU.1 is inactivated by AML1-ETO in $\mathrm{t}(8 ; 21)$ myeloid leukemia. Blood 2003, 101:270-277.

20. Lo CF, Pisegna S, Diverio D: The AML1 gene: a transcription factor involved in the pathogenesis of myeloid and lymphoid leukemias. Haematologica 1997, 82:364-370.

21. Pollock JL, Westervelt P, Walter MJ, Lane AA, Ley TJ: Mouse models of acute promyelocytic leukemia. Curr Opin Hematol 2001, 8:206-211.

22. Chan IT, Kutok JL, Williams IR, Cohen S, Moore S, Shigematsu H, Ley TJ, Akashi K, Le Beau MM, Gilliland DG: Oncogenic K-ras cooperates with PML-RAR alpha to induce an acute promyelocytic leukemia-like disease. Blood 2006, 108:1708-1715.

23. Kelly LM, Kutok JL, Williams IR, Boulton CL, Amaral SM, Curley DP, Ley TJ, Gilliland DG: PML/RARalpha and FLT3-ITD induce an APL-like disease in a mouse model. Proc Natl Acad Sci U S A 2002, 99:8283-8288.

24. Kogan SC, Brown DE, Shultz DB, Truong BT, Lallemand-Breitenbach V, Guillemin MC, Lagasse E, Weissman IL, Bishop JM: BCL-2 cooperates with promyelocytic leukemia retinoic acid receptor alpha chimeric protein (PMLRARalpha) to block neutrophil differentiation and initiate acute leukemia. J Exp Med 2001, 193:531-543.

25. Walter MJ, Park JS, Ries RE, Lau SK, McLellan M, Jaeger S, Wilson RK, Mardis ER, Ley TJ: Reduced PU.1 expression causes myeloid progenitor expansion and increased leukemia penetrance in mice expressing PML-RARalpha. Proc Natl Acad Sci U S A 2005, 102:12513-12518.

doi:10.1186/1756-8722-5-22

Cite this article as: Zhu et al:: The significance of low PU.1 expression in patients with acute promyelocytic leukemia. Journal of Hematology \& Oncology 2012 5:22.

\section{Submit your next manuscript to BioMed Central and take full advantage of:}

- Convenient online submission

- Thorough peer review

- No space constraints or color figure charges

- Immediate publication on acceptance

- Inclusion in PubMed, CAS, Scopus and Google Scholar

- Research which is freely available for redistribution 